\title{
Scleral homograft inlay for correction of cicatricial entropion and trichiasis
}

\author{
CHAKKO PUTHENPURAYIL THOMMY \\ From the Guinness Ophthalmic Unit, Ahmadu Bello University Hospital, Kaduna, Nigeria
}

SUMMARY In the management of trachomatous cicatricial entropion and trichiasis numerous surgical options are available to the surgeon, who, however, must choose the correct technique suitable to the severity of the condition. In general, severe cases do better with a graft of mucous membrane or skin. In this paper the use of another graft material, homologous sclera, in correcting entropion and trichiasis is discussed. A 1.5 to $2 \mathrm{~mm}$ wide strip of fresh or preserved sclera was used as an inlay in a grey-line split technique with severance of pretarsal and Riolan's fibres in 155 entropion corrections in 136 patients. There was a success rate of $92.3 \%$ during the observation period of 15 months. Isolated trichiatic lashes were seen in $7.7 \%$. Minor complications occurred, such as granulomas and partial sloughing of grafts, but did not affect the ultimate results.

Homograft in ophthalmic surgery is well established. The sclera excites a minimal reaction, and host acceptance is almost universal. In 1951 Lister $^{1}$ reported the use of corneoscleral grafts in 3 cases. Human sclera has been used as a supporting sling in posterior ectasia of high myopia, ${ }^{2}$ for repair of perforating injury of the eye, ${ }^{3}$ as an overlay in chronic scleromalacia perforans, ${ }^{4}$ in retinal detachment surgery, ${ }^{5-8}$ for covering exposed orbital implants, ${ }^{9}$ for reinforcing the anterior socket wall in extruding orbital implants, ${ }^{10}$ as a primary procedure in enucleation surgery to prevent extrusion of implant, ${ }^{11}$ as an overlay graft in intercalary staphyloma,$^{12}$ in herniation of the choroid,,$^{13}$ and to close a perforated corneal ulcer. ${ }^{14}$ Homologous sclera was also used in surgery of the eye lids, for correcting ptosis, ${ }^{15}$ and cicatricial entropion. ${ }^{16}$ Rubenzik et al ${ }^{16}$ used banked scleral graft to rectify the shrinkage and deformity of the posterior lamella of the upper lid.

Various methods for preserving sclera were employed in previous studies, such as quick freezing, ${ }^{15}$ keeping in alcohol, ${ }^{4}{ }^{7}$ in xylol, ${ }^{5}$ or in anhydrous glycerin (molecular sieve). ${ }^{6} 8917$

Bacteriological studies of donor sclera were negative in $91 \%$, positive in $4 \%$, and not reported in $5 \% \cdot{ }^{8}$ No infection occurred even when bacteriologically positive sclera were used. ${ }^{8}$ No cases of

Correspondence to $\mathrm{Dr}$ Chakko P. Thommy, Guinness Ophthalmic Unit, Ahmadu Bello University Hospital, PMB 2016, Kaduna, Nigeria.
Table 1 Patients (155 eyes)

\begin{tabular}{lll}
\hline Age group & Male & Female \\
\hline $20-30$ & 4 & 36 \\
$31-40$ & 5 & 52 \\
$41-50$ & - & 33 \\
$51-60$ & - & 6 \\
Total & 9 & 127 \\
\hline
\end{tabular}

sympathetic ophthalmitis were reported by any of the authors.

In this study fresh or preserved scleral strip is used as an inlay in a grey-line split technique, combined with severance of pretarsal and Riolan's fibres of the orbicularis to redirect the lash line. The ready availability of sclera, the ease of preserving it, the technical feasibility, and the absence of complications from its use in previous reports prompted this study.

\section{Material and methods}

This study was conducted at the Guinness Ophthalmic Unit of Ahmadu Bello University Hospital, Kaduna, Nigeria, between October 1978 and December 1979. 155 upper lid entropion corrections with homologous scleral strips as inlay were done in 136 patients. Female patients predominated. The youngest patient was 20 years and the oldest 60 . The maximum numbers were in the age group 20 to 40 years (Table 1). The maximum follow-up period 
Table 2 Follow-up

\begin{tabular}{lll}
\hline Period (months) & Number of eyes & Percentage \\
\hline 2 & 23 & $14 \cdot 82$ \\
3 to 6 & 43 & $27 \cdot 74$ \\
7 to 10 & 71 & $45 \cdot 80$ \\
11 to 15 & 18 & $11 \cdot 64$ \\
\hline
\end{tabular}

was 15 months and the minimum 2 months (Table 2).

Since we do not have an eye bank we depend for our supply of human sclera on the enucleated eyes in our department. The causes of enucleation are usually trauma and unsightly staphylomas. The eyeball is thoroughly cleaned and all remnants of muscles and episcleral tissues are excised. It is opened at the limbus and the cornea is excised. The contents are eviscerated and then the scleral coat is turned inside out over the thumb. A piece of gauze is used to clear away any remaining uveal tissue. The strips are cut in 2 ways: (1) spirally starting at the limbus, which is then cut into desired lengths; $;^{15}$ (2) the sclera is cut in half anteroposteriorly, and then strips are cut in single lengths.

The width of each strip is 1.5 to $2 \mathrm{~mm}$. Wider strips are not desirable unless the grey-line split in the lid is deeper than $3 \mathrm{~mm}$. The strips are kept in Neosporin solution (neomycin sulphate, gramicidin, polymyxin B sulphate) until used.

Most often the sclera is used fresh. When more sclera is available, it is simply preserved in $95 \%$ sterile glycerin without molecular sieve after immersion in Neosporin solution for about 2 hours and then kept in the refrigerator. The longest period of such preservation has been 3 months. Random specimens are taken from both fresh and preserved sclera for bacteriological culture.

\section{TECHNIQUE}

This procedure is a modification of Thommy's skin graft method of entropion correction. ${ }^{18}$ A scleral strip is used instead of skin graft. The upper lid is split in the grey line for the whole length, the incision being extended upwards for 3 to $5 \mathrm{~mm}$ after the last lash at both ends, medially avoiding the punctum (Fig. 1). The incision is deepened commensurate with the severity of entropion and the correction needed. The posterior flap is inspected to see if any lash roots are left on it. If they are, they should be excised completely. A very thickened and distorted tarsal plate, as is usually the case in severe trachomatous entropion, is excised to the desired thickness. The strip of sclera is now placed in the incisional groove with the ends lying in the upward cuts. I suture this in position, starting at 1 upward incision and keeping the end of the scleral strip flush with the skin surface. The $5 / 0$ silk mattress sutures are tied over the anterior surface of the lid at a distance from the lid margin to effect the desired lift of the anterior cilia-bearing flap (Fig. 2). Partial scleral inlays may be done at either end or in the middle portion of the lid when trichiasis involves only these limited areas.

Antibiotic ointment is applied and the eye patched. The patch is removed on the third day. The mattress sutures are removed on 7th or 8th day. Follow-up is every 2 weeks for 1 month and then monthly for 4 months, continued later 4-monthly. In cases of partial failure, when 1 or 2 lashes grow down, the trichiatic lashes are treated with electrolysis.

This method may be used for entropion of the lower lid also. The procedure is greatly helped if the author's lid clamps ${ }^{18}$ are used. They conveniently hold the lids, expose the whole lid for unhindered surgery, control bleeding, and protect the eye ball at the same time.

\section{Results}

No change in the donor sclera was noticed by the simple preservation of sclera in glycerin for short

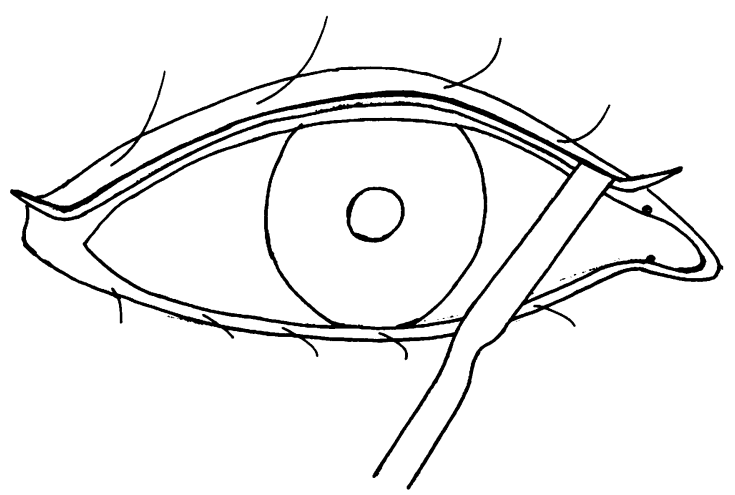

Fig. 1 Scleral homograft inlay. Grey-line incision extended upwards at both ends.

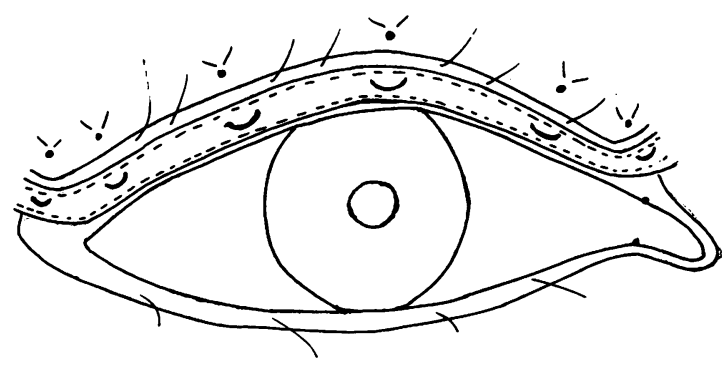

Fig. 2 Scleral homograft inlay. Scleral strip inlaid and sutured. 
Table 3 Results

\begin{tabular}{llllll}
\hline & \multicolumn{2}{l}{ Recurrence } & & \multicolumn{2}{l}{ Success } \\
\cline { 2 - 3 } \cline { 5 - 6 } \cline { 5 - 6 } & Number & Percentage & & Number & Percentage \\
\hline Entropion & 0 & 0 & 155 & 100 \\
Trichiasis & 12 & $7 \cdot 7$ & 143 & $92 \cdot 3$ \\
\hline
\end{tabular}

Table 4 Complications

\begin{tabular}{lcc}
\hline Complication & Number & Percentage \\
\hline Granuloma formation & 16 & $10 \cdot 3$ \\
Partial sloughing of graft & 4 & $2 \cdot 6$ \\
\hline
\end{tabular}

periods in this study. Random bacteriological studies of scleral strips were always negative. There was no postoperative infection and no recurrence of entropion in any case. However, trichiasis recurred in 12 eyes. This occurred as isolated growths of lashes from the lower (posterior) lid flap. Thus scleral inlays in these cases of entropion and trichiasis were successful in 143 eyes $(92.3 \%)$ and failed in $7.7 \%$ (Table 3).

The following complications were seen, but they did not affect the success of the technique. Small granulomas over the scleral strip at the suture sites were seen from 1 to 2 weeks postoperatively in 16 lids $-10.3 \%$. These were excised and did not recur. Partial sloughing of the scleral strip was noticed in 4 lids $(2 \cdot 6 \%)$ (Table 4$)$.

\section{Discussion}

Clinical experience ${ }^{1-15}$ and experimental evidence ${ }^{20}$ show that human sclera is an excellent biological material that can be utilised in various situations in ophthalmic surgery. It is strong yet flexible, and so its manoeuvrability is excellent. It undergoes very little change over long periods and excites minimal reaction..$^{20}$ It is readily available wherever an eye bank exists. Even where there is no eyebank, sclera is not difficult to get, because severe trauma to the eye and uncomplicated but unsightly staphylomas are common conditions necessitating enucleation. Staphylomas were the sources of sclera in this study, and no problems were encountered in the use of sclera from such sources. Preservation of sclera is also simple. The method used in this study was dehydration in sterile glycerin and refrigeration. Since the sclera was used up within 3 months, absolute dehydration by molecular sieve was not essential, and the sclera suffered no harm from the method used here. Random bacteriological studies of antibiotic treated scleral specimens were negative.
More detailed or routine bacteriological studies before every operation were not undertaken because of (1) favourable reports from an earlier study, ${ }^{8}$ (2) negative reports in random samples, (3) the aseptic method of enucleation, (4) the antibiotic treatment of the sclera, and (5) the exposed position of the scleral strip on the lid. Moreover, as the study proceeded, no infection was encountered in any case.

Sympathetic ophthalmia has been considered a serious deterrent to the use of sclera in ophthalmic surgery. However, no cases of such uveitis have been reported after donor sclera was used in ophthalmic surgery from $1948^{14}$ for various conditions. Moreover, sympathetic ophthalmitis is extremely rare or absent in Africans, the aboriginals of Australia and New Zealand, and in the south-west Pacific area ${ }^{21}$ and it is becoming a thing of the past in all races because of refinements in surgical techniques, particularly in ocular traumatic surgery.

Extreme degrees of entropion and trichiasis resulting from trachomatous cicatrix often necessitate maximum mobilisation of the cilia-bearing anterior layer of the lid and grafting in the exposed area with either mucous membrane ${ }^{22}$ or skin. ${ }^{18}$ The mobilisation of the anterior layer is greatly aided by the technique of dividing the pretarsal fibres of the orbicularis and the anterior fibres of Riolan's muscle at both ends of the lid, as is done in Thommy's skin graft technique ${ }^{18}$ and in this present technique. The division of orbicularis fibres at the lower part of the upper lid greatly aids healing in the position in which the lid is surgically repaired by abolishing the element of spasm which accompanies entropion and trichiasis. The interposition of the ends of the scleral strip in the upward cuts prevents reunion of the lower orbicularis fibres, thus maintaining the corrected position of the lid. The scleral strip inlay has advantages because of its inherent optimum thickness, strength, and flexibility. Its ready availability and ease of preservation in prepared strips make the surgery much simpler and quicker. Scleral tissue remains unchanged over a long period of time, ${ }^{20}$ which enhances the mechanical effects of the surgical technique.

The success of the procedure depends also on (1) careful excision of thickened and distorted tarsal plate and (2) the careful inspection of the lower (posterior) flap for any lash roots, which, if present, must be completely removed. The incidence of isolated trichiatic lashes in $7 \cdot 7 \%$ of cases in this study can be directly attributed to not being careful during this step of the procedure.

Granuloma in $10.3 \%$ of the cases appeared to be a reaction to the silk sutures, because the lesions were related to the suture sites on the scleral inlay. 


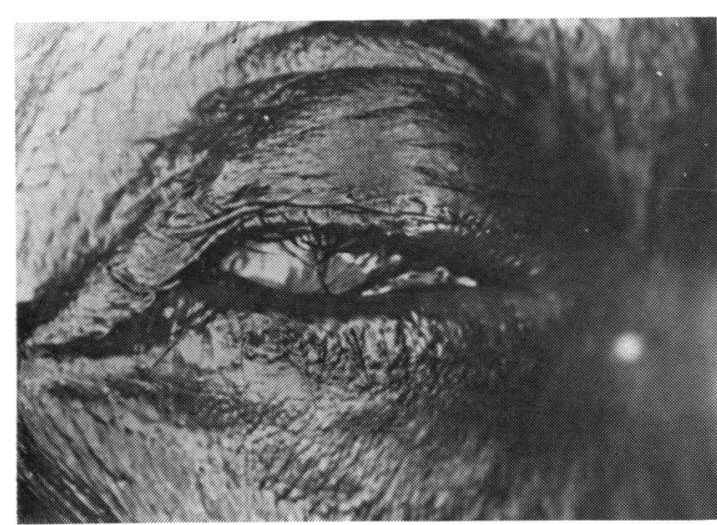

Fig. 3 Scleral homograft inlay. The usual entropion/ trichiasis encountered in our clinic.

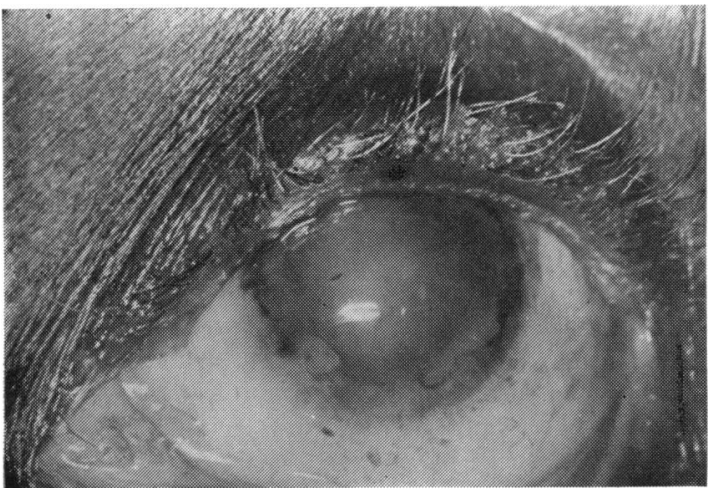

Fig. 4 Scleral homograft inlay. The corrected upper lid.

Partial sloughing of the scleral strip in $2.6 \%$ may be related to the initial condition of the donor sclera.

This procedure of scleral inlay to correct trachomatous cicatricial entropion and trichiasis was found to be effective from this study $(92 \cdot 3 \%)$ with minimal complications. Cosmetically the results are excellent (Figs. 3 and 4).

\section{References}

1 Lister A. Malignant pigmented tumours in the neighbourhood of limbus treated by radical excision followed by corneoscleral grafts. Report of three cases. Trans Ophthalmol Soc UK 1951; 71: 97-110.

2 Borley WE, Snyder AA. Surgical treatment of high myopia. Trans Am Acad Ophthalmol Otolaryngol 1958; 62: 791-802.

3 Kanagasundaram CR. Repair of perforating injury with a scleral graft. Br J Ophthalmol 1959; 43: 440-1.

4 Obear MF, Winter FC. Technic of overlay scleral homograft. Arch Ophthalmol 1964; 71: 837-8.

5 Rodrigues-Vasques F. New implant material for retinal detachment surgery. Am J Ophthalmol 1962; 53: 937-43.

6 Wilson FM. Homografts of preserved sclera in retinal detachment surgery. Arch Ophthalmol 1964; 72: 212-8.

7 Knobloch WH, Cibis PA. Retinal detachment surgery with preserved human sclera. Am J Ophthalmol 1965; 60: 191-201.

8 Ogawa GM, Carey JD. Homologous scleral explant buckles in retinal detachment surgery. Am J Ophthalmol 1974; 77: 505-8.

9 Helveston EM. Human bank scleral patch. Arch Ophthalmol 1969; 82: 83-6.

10 Zolli C, Shannon GM. Experience with donor sclera for extruding orbital implant. Ophthalmic Surg 1977;8: 63-70.

11 Soll DB. Donor sclera in enucleation surgery. Arch Ophthalmol 1974; 92: 494-5.

12 Goldberg MF, Ryan SJ. Intercalary staphyloma in Marfan's syndrome. Am J Ophthalmol 1969; 67: 329-34.

13 Sivasubramaniam P, Hoole T. Hernia of the choroid treated by scleral grafting followed by direct suturing of the sclera. Br J Ophthalmol 1954; 38: 126-7.

14 Larsson S. Treatment of perforated corneal ulcer by autoplastic scleral transplantation. $\mathrm{Br} J$ Ophthalmol 1948; 32: 54-7.

15 Bodian M. Repair of ptosis using human sclera. Am J Ophthalmol 1968; 65: 352-8.

16 Rubenzik R, Tenzel RR, Miller GR. Repair of cicatricial entropion of the upper eye lid. Am J Ophthalmol 1975; 80: $302-3$.

17 King JH, McTique JW, Merryman HT. A simple method of preservation of corneas for lamellar keratoplasty. Am J Ophthalmol 1962; 53: 445-9.

18 Thommy CP. A modified technique for correction of trachomatous cicatricial entropion. Br JOphthalmol 1980; 64: 296-8.

19 Thommy CP. A new lid clamp. Br J Ophthalmol 1980; 64: 940 .

20 Johnson WA, Henderson JW, Park Hill EM, Grindlay JS. Transplantation of homografts of sclera - an experimental study. Am J Ophthalmol 1962; 54: 1019-30.

21 Duke-Elder S, Perkins ES. Diseases of the uveal tract: In: Duke-Elder S, ed. System of Ophthalmology. London: Kimpton, 1966: 9: 562-4.

22 Callahan A, Dortzbach RK. Correction of cicatricial entropion of the upper lid. In: Mustarde JC, Jones LT, Callahan A, eds. Ophthalmic Plastic Surgery Up to Date. Birmingham, Alabama: Aesculapius, 1970: 76-84. 